\title{
Cannabinoids reverse the effects of early stress on neurocognitive performance in adulthood
}

\author{
Shirley Alteba, ${ }^{1,2}$ Nachshon Korem, ${ }^{1,2}$ and Irit Akirav ${ }^{1}$ \\ ${ }^{1}$ Department of Psychology, University of Haifa, Haifa 3498838, Israel
}

\begin{abstract}
Early life stress (ES) significantly increases predisposition to psychopathologies. Cannabinoids may cause cognitive deficits and exacerbate the effects of ES. Nevertheless, the endocannabinoid system has been suggested as a therapeutic target for the treatment of stress- and anxiety-related disorders. Here we examined whether cannabinoids administered during "late adolescence" (extensive cannabis use in humans at the ages 18-25) could reverse the long-term adverse effects of ES on neurocognitive function in adulthood. Male and female rats were exposed to ES during post-natal days (P) 7-14, injected with the cannabinoid CBl/2 receptor agonist WIN55,212-2 (WIN; $1.2 \mathrm{mg} / \mathrm{kg}$, i.p.) for 2 wk during late adolescence (P45-60) and tested in adulthood (P90) for working memory, anxiety, and alterations in CB1 receptors (CBIr), and glucocorticoid receptors (GRs) in the stress circuit [hippocampus, prefrontal cortex (PFC), and basolateral amygdala (BLA)]. ES males and females exhibited impaired performance in short-term memory in adulthood in the spatial location and social recognition tasks; males were also impaired in the novel object recognition task. WIN administered during late adolescence prevented these stress-induced impairments and reduced anxiety levels. WIN normalized the ES-induced up-regulation in PFC-GRs and CAl-CBIr in females. In males, WIN normalized the ES-induced up-regulation in PFC-GR and down-regulation in BLA-CBlr. There is a crucial role of the endocannabinoid system in the effects of early life stress on behavior at adulthood. Differences in recognition memory and in the expression of GRs and CBlr in the fear circuit suggest sex differences in the mechanism underlying coping with stress.
\end{abstract}

The endocannabinoid (eCB) system has recently emerged as a promising therapeutic target for the treatment of stress-related emotional disorders (Marsicano et al. 2002; Hill and Gorzalka 2009; Moreira and Wotjak 2010; Ganon-Elazar and Akirav 2012, 2013; Korem and Akirav 2014). Animal studies show that cannabinoid agonists promote antidepressant- and anxiolytic-like responses (Bortolato et al. 2007; McLaughlin et al. 2007; GanonElazar and Akirav 2012; Abush and Akirav 2013; Segev et al. 2013).

Traumatic experiences during early developmental periods might be associated with psychopathology (such as depression, anxiety disorders, and schizophrenia) and altered neuroendocrine function later in life (Levine 2005). Early life stress disrupts the programming of the hypothalamic-pituitary-adrenal (HPA) axis and the brain's stress circuit [hippocampus, amygdala, and prefrontal cortex (PFC)]; These are considered critical mediators of the effects of early life trauma on later life compromised mental health in humans and animal models (Glaser 2000; Champagne et al. 2008; Lupien et al. 2009).

In general, cannabinoids can impair cognitive function (Riedel and Davies 2005). Animal and human studies suggest that frequent exposure to cannabis during "adolescence" may have long-term adverse effects on the development of cognition, brain structure, and function (for review, see O'Shea et al. 2006; Jager and Ramsey 2008; Rubino et al. 2008; Rubino and Parolaro 2016). Exposure to cannabinoids in adolescent rodents decreased social behavior later in life in both sexes and impaired visually guided and spatial version of the novel object recognition test in adulthood in rodents (Schneider and Koch 2003; O'Shea et al. 2004, 2006; Realini et al. 2011; Rubino et al. 2015).

However, studies on adults were not straightforward in determining whether cognitive deficits, observed after only hours or

\footnotetext{
${ }^{2}$ These authors contributed equally to this work. Corresponding author: irit.akirav@gmail.com

Article is online at http://www.learnmem.org/cgi/doi/10.1101//m.041608.116.
}

days of abstinence, are temporary or long-lasting. For example, Quinn et al. (2008) found deficits in object recognition following repeated exposure to $\Delta^{9}$-THC in adolescent but not adult rats, a result consistent with other reports of cannabinoid administration in immature but not mature rats causing lasting impairments in learning (O'Shea et al. 2004; Schneider and Koch 2007).

It is difficult to define the time course of adolescence, with no single event signaling its onset or termination (Spear 2000). Per definition, adolescence covers the complete time span from childhood (shortly before puberty) to adulthood, including the pubertal period. Previous studies have suggested the time window from P28 to P42 as a prototypic period during which rats of most breeding stocks exhibit adolescent-typical characteristics, although this does not imply that older and younger animals cannot be considered as adolescents (for review, see Schneider 2013; Spear 2000). We use the term "adolescence" for the time window P28-45 and the term "late adolescence" for P45-60 (Abush and Akirav 2012).

We have shown that $2 \mathrm{wk}$ administration of the CB1/2 receptor agonist WIN55,212-2 (WIN) during late adolescence (postnatal day (P) 45-60) impaired hippocampal dependent short-term memory measured in the object location task even $75 \mathrm{~d}$ after the last drug injection (Abush and Akirav 2012). However, there were no long-term effects on other memory tasks (Morris water maze, novel object recognition) and plasticity. Moreover, we have recently shown (Abush and Akirav 2013) that in rats exposed to chronic stress ( 2 wk restraint) and chronic cannabinoid administration ( 2 wk WIN) during the late-adolescence period, WIN prevented the stress-induced impairment in LTP and short-term

(C) 2016 Alteba et al. This article is distributed exclusively by Cold Spring Harbor Laboratory Press for the first 12 months after the full-issue publication date (see http://learnmem.cshlp.org/site/misc/terms.xhtml). After 12 months, it is available under a Creative Commons License (AttributionNonCommercial 4.0 International), as described at http://creativecommons. org/licenses/by-nc/4.0/. 
memory. This suggested beneficial effects of WIN on memory when administered in proximity to stress exposure (Abush and Akirav 2013).

Studies that examined the effects of both ES and cannabinoids on behavioral and physiological responses in adulthood suggested that early maternal deprivation and adolescent cannabinoid exposure exert distinct sex-dependent long-term behavioral and physiological modifications that could predispose to the development of certain neuropsychiatric disorders (LlorenteBerzal et al. 2011; López-Gallardo et al. 2012; Zamberletti et al. 2012). In general, there are sex differences in emotional behaviors and in response to cannabinoids (Maren et al. 1994; Viveros et al. 2012).

Here we aimed to examine the long-term neurocognitive effects of chronic administration of cannabinoids during late adolescence in male and females rats that were subjected to "earlylife exposure" of maternal neglect. Importantly, a high percentage of cannabis use $(\sim 40 \%)$ is among young adults at the ages of $18-$ 25 (equivalent to the late-adolescent period). We used a natural rat model of early-life abuse; in this model the mother handles her pups roughly when provided with insufficient bedding for nest building (Raineki et al. 2010). We also examined whether early stress and cannabinoids alter the expression of glucocorticoid receptors (GRs) and cannabinoid CB1 receptors (CB1r) in the brain's stress circuit where these receptors are highly abundant (Ahima and Harlan 1990; Herkenham et al. 1990; Katona et al. 2001; Marsicano and Kuner 2008; Sivukhina et al. 2013).

\section{Results}

\section{The effects of exposure to early stress and WIN55,212-2 on behavior}

Similar to the effects observed in Raineki et al. (2010), the mothers in the stress condition demonstrated less maternal behavior $\left(t_{(14)}=4.617, P<0.001\right)$ and more harmful behavior toward pups $\left(t_{(14)}=6.925, P<0.001\right)$. There was no effect on self-activity $\left(t_{(14)}<1\right.$, NS) (Table 1; Values are the percentage of observation periods in which behaviors occurred).

Also, no significant difference in weight between early stressed and nonstressed pups was found throughout the experiment $\left(F_{(1,56)}<1\right.$, NS; data not shown) which corresponds to Raineki et al. (2010).

Observations were made in the morning (9-12), noon (12-14), or afternoon (14-16) for $15 \mathrm{~min}$. Repeated-measures

Table 1. Frequency of maternal behaviors observed during mother-infant interactions in the early stress model

\section{NoES}

ES

\begin{tabular}{lll}
\hline $\begin{array}{l}\text { Maternal activity } \\
\text { Nursing, licking pups, gathering } \\
\text { pups (nesting) }\end{array}$ & $31.9 \% \pm 2.73$ & $18.91 \% \pm 1.8^{* * *}$ \\
$\begin{array}{l}\text { Self-activity-Dams } \\
\text { Feeding, cleaning itself, } \\
\text { exploring }\end{array}$ & & \\
$\begin{array}{l}\text { Harmful behavior toward } \\
\text { pups }\end{array}$ & $66.64 \% \pm 4.91$ & $70.16 \% \pm 5.0$ \\
$\begin{array}{l}\text { Step or jump on, rough handling, } \\
\text { isolating, tossing around }\end{array}$ & $1.46 \pm 0.77$ & $10.92 \pm 0.89^{* * *}$ \\
\hline
\end{tabular}

Cages were observed three times a day (morning, noon, and afternoon) from P7 to P14. During these times the mothers in the stress condition demonstrated less maternal behavior (nursing, cleaning pups, gathering pups), and harmful behavior toward pups (step-on, rough handling, isolating pups, and tossing around). There was no effect on self-activity (self-feeding, selfcleaning exploring). Values are the percentage of observation periods in which behaviors occurred $(* * * P<0.001)$.
ANOVA comparing the different times of observation revealed a significant effect in "self-activity" in the ES group $\left(F_{(2,19)}=\right.$ 12.951, $P<0.001)$. Post hoc comparison revealed that during the afternoon hours, mothers from the ES group were more engaged in self-activity $(P<0.01)$.

See Figure 1 for a diagram illustrating the experimental design.

Male and female rats exposed to ES were tested on P23 in the social interaction test. Unpaired $t$-test revealed that ES males $\left(t_{(30)}=-3.583, P<0.01\right.$; Fig. $\left.2 \mathrm{~A}\right)$ and ES females $\left(t_{(30)}=-6.836, P<0.001\right.$; Fig. $\left.2 \mathrm{~B}\right)$ demonstrated less social behaviors than their NoES controls. These findings corroborate with previous studies (Raineki et al. 2012).

Next we examined the effects of ES and WIN on short-term/ working memory in adulthood. Memory was tested 30 min after the sample in order to measure short-term memory as accumulating evidence suggested that cannabinoids impair short-term memory and working memory (for review, see Lichtman et al. 2002; Riedel and Davies 2005; Egerton et al. 2006).

The data were analyzed using three-way ANOVA with ES, sex, and drug as between-subject factors $(2 \times 2)$, and DI as the dependent variable. Post hoc tests were not performed for ES, sex, and drug as there are fewer than three groups. We used one-sample $t$-test on each group in order to reveal a significant difference from the $50 \%$ DI (i.e., chance level) as an exploration score $>0.5$ implies greater exploration of the object in the novel location.

For the "object location task" (Fig. 3A,B), a significant effect was found for drug $\left(F_{(1,56)}=4.781, P<0.05\right)$ suggesting that WIN-treated rats performed better than vehicle-treated rats. A significant $\mathrm{ES} \times$ drug interaction $\left(F_{(1,56)}=9.650, P<0.01\right)$ was also found. Independent $t$-test revealed that ES male rats treated with vehicle performed worse than NoES rats treated with vehicle $\left(t_{(14)}=-3.356, P<0.01\right)$.

In males (Fig. 3A) one-sample $t$-test performed on each group revealed a significant difference from the $50 \%$ DI (i.e., chance level) in the NoES + veh $\left(t_{(7)}=6.650, P<0.001\right)$ and $\mathrm{ES}+\mathrm{WIN}$ $\left(t_{(7)}=5.628, P<0.01\right)$ groups, suggesting intact performance in the task. No such difference was found in the ES + veh $\left(t_{(7)}=\right.$ 0.370 , NS) group suggesting poor performance. The NoES + WIN group also demonstrated poor performance $\left(t_{(7)}=2.170\right.$, $P=0.067)$, corroborating with a previous study from our laboratory (Abush and Akirav 2012). No significant differences in total exploration time were found in males in the sample $\left(F_{(3,32)}=1.013\right.$, NS) or test $\left(F_{(3,32)}=1.14\right.$, NS) phase.

In females (Fig. 3B), one-sample $t$-test revealed a significant difference from the $50 \%$ DI in the NoES + veh $\left(t_{(7)}=3.143, P<\right.$ $0.05), \mathrm{NoES}+\mathrm{WIN}\left(t_{(7)}=2.904, P<0.05\right)$ and ES + WIN $\left(t_{(7)}=\right.$ $5.158, P<0.01)$ groups, suggesting intact performance in the task. No such difference was found in the ES + veh group $\left(t_{(7)}=\right.$ 1.600, NS) suggesting poor performance. No significant differences in total exploration time were found in the test phase $\left(F_{(3,32)}=\right.$ 1.173 , NS), but during the sample phase, females injected with WIN explored the objects less than the other groups $\left(F_{(3,32)}=\right.$ 3.489, $P=0.029$ ).

For the social recognition task (Fig. 3C,D), a significant effect was found for drug $\left(F_{(1,64)}=23.609, P<0.001\right)$ suggesting that WIN-treated rats performed better than vehicle-treated rats. A significant ES $\times$ drug interaction $\left(F_{(1,56)}=5.915, P<0.05\right)$ was also found. Independent $t$-test revealed that ES rats treated with WIN performed better than ES rats treated with vehicle $\left(t_{(30)}=4.838\right.$, $P<0.001)$.

In males (Fig. 3C), one-sample $t$-test revealed a significant difference from the $50 \%$ DI in the NoES + veh $\left(t_{(7)}=3.634\right.$, $P<0.01)$, NoES + WIN $\left(t_{(7)}=5.782, P<0.01\right)$, and ES + WIN $\left(t_{(7)}=4.415, P<0.01\right)$ groups, suggesting intact performance. No such difference was found in the ES + veh group $\left(t_{(7)}=-1.347\right.$, 


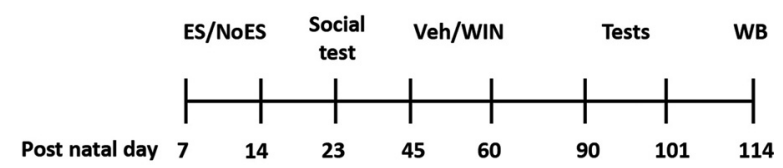

Figure 1. Experimental design. The dam and her pups were housed in a cage with limited [early stress (ES)] or abundant (NoES) bedding material from P7 to P14. On day 23, pups were exposed to a social interaction test to verify that early stress exposure results in impaired social behavior. During the late-adolescence period (P45-P60) rats received 14 injections of vehicle (veh) or the CB1/2 agonist WIN. On P90 rats were taken to neurocognitive tests (object location, object recognition, and social recognition) and to the open field for an anxiety test (P90-94: habituation to the memory tests arena; P95-96: object recognition; P97-98: object location; P99-100 social recognition; P101: open field). On P114 brains were taken for Western blot (WB) analysis.

NS). No significant differences in total exploration time were found in males in the sample $\left(F_{(3,32)}<1\right.$, NS) or test $\left(F_{(3,32)}=\right.$ $1.377, \mathrm{NS}$ ) phase.

In females (Fig. 3D), one-sample $t$-test revealed a significant difference from the $50 \% \mathrm{DI}$ in the NoES + veh $\left(t_{(7)}=2.356, P=\right.$ $0.50)$, NoES $+\mathrm{WIN}\left(t_{(7)}=3.267, P<0.05\right)$, and ES $+\mathrm{WIN}\left(t_{(7)}=\right.$ $3.563, P<0.01)$ groups, suggesting intact performance. No such difference was found in the ES + veh group $\left(t_{(7)}=-0.664, \mathrm{NS}\right)$. No significant differences in total exploration time were found in the sample $\left(F_{(3,32)}=1.385\right.$, NS) or test $\left(F_{(3,32)}<1\right.$, NS) phase.

For the novel object recognition task (Fig. 3E,F), a significant effect was found for drug $\left(F_{(1,56)}=11.070, P<0.01\right)$ suggesting that WIN-treated rats performed better than vehicle-treated rats. A significant ES $\times$ drug interaction $\left(F_{(1,56)}=6.283, P<0.05\right)$ was also found. Independent $t$-test revealed that ES rats treated with WIN performed better than ES rats treated with vehicle $\left(t_{(30)}=\right.$ 4.336, $P<0.001)$.

In males (Fig. 3E) one-sample $t$-test revealed a significant difference from the $50 \% \mathrm{DI}$ in the NoES $+\operatorname{veh}\left(t_{(7)}=2.525, P<0.05\right)$, NoES + WIN $\left(t_{(7)}=3.250, P<0.01\right)$, and ES + WIN $\left(t_{(7)}=3.710\right.$, $P<0.01)$ groups, suggesting intact performance. No such difference was found in the ES + veh group $\left(t_{(7)}=1.556\right.$,NS). No significant differences in total exploration time were found in males in the sample $\left(F_{(3,32)}<1\right.$, NS) or test $\left(F_{(3,32)}=1.49, \mathrm{NS}\right)$ phase.

In females (Fig. 3F), one-sample $t$-test revealed a significant difference from the 50\% DI in the NoES + veh $\left(t_{(7)}=3.498, P<\right.$ $0.05), \quad \mathrm{NoES}+\mathrm{WIN}\left(t_{(7)}=3.777, P<0.01\right), \mathrm{ES}+\mathrm{WIN}\left(t_{(7)}=\right.$ $9.608, P<0.001)$ and the ES + veh $\left(t_{(7)}=4.656, P<0.01\right)$ groups, suggesting intact performance in all groups. No significant differences in total exploration time were found in the test phase $\left(F_{(3,32)}<1\right.$, NS). However, during the sample phase, females injected with WIN explored the objects less than the other groups $\left(F_{(3,32)}=4.437, P=0.022\right)$, similar to the effect on exploration time observed in the object location task.

We also measured anxiety levels in the open field test (Fig. 4A,C). Three-way ANOVA with ES, sex, and drug as betweensubject factors $(2 \times 2)$, and anxiety index as the dependent variable revealed a significant effect for drug $\left(F_{(1,56)}=16.103, P<\right.$ 0.001 ) suggesting that WIN-treated rats demonstrate a lower anxiety index than vehicle-treated rats, and a significant effect for sex $\left(F_{(1,56)}=4.113, P<0.05\right)$ suggesting that males demonstrate a lower anxiety index than females.

There were no significant differences in total line crossings (Fig. 4B,D).

Findings in the literature suggest that cannabinoid administration during the adolescence period after ES has impairing effects on emotional behavior and memory (Schneider and Koch 2003; Macrì and Laviola 2004; O'Shea et al. 2004; Biscaia et al. 2008). Hence, we examined, using our protocols, whether cannabinoids administered during the adolescence pe- riod would affect short-term memory and anxiety in ES rats. ES male rats were administered with the agonist WIN or vehicle during P30-P45 and tested on P75 and onward. See Figure 5A for a diagram illustrating the experimental design for the adolescent group.

Unpaired $t$-test revealed that the ES + WIN group demonstrated less exploration than the ES + veh group of the novel location $\left(t_{(14)}=-2.881, P<0.05\right.$; Fig. 5B). One-sample $t$-test revealed a significant difference from the $50 \%$ DI in the ES + veh group in the object location $\left(t_{(7)}=2.644, P<0.05\right)$, but not in the ES + WIN group $\left(t_{(7)}=-1.488, N S\right)$, suggesting impaired performance. The NoES group performed well in the spatial location task (significantly different from the $50 \% \mathrm{DI} ; \mathrm{M}=0.63, \mathrm{SEM}= \pm 0.02 ; t_{(7)}=$ 2.86, $P<0.05$ ).

In the social recognition task, the ES + WIN group demonstrated less exploration of the novel juvenile than the ES + veh group $\left(t_{(14)}=-3.126, P<0.01\right.$; Fig. $\left.5 C\right)$. One-sample $t$-test revealed a significant difference from the $50 \%$ DI in the ES + WIN group $\left(t_{(7)}=-2.877, P<0.05\right)$ that significantly failed to reach chance level $(M=0.440, S E M= \pm 0.020)$, and no significant difference from the DI in the ES+ veh group $\left(t_{(7)}=1.510, N S\right)$ suggesting poor performance in both groups. The NoES group performed well in the spatial location task (significantly different from the $50 \% \mathrm{DI} ; \mathrm{M}=0.60, \mathrm{SEM}= \pm 0.03 ; t_{(7)}=2.78, P<0.05$ ).

No significant differences in exploration time were found in the novel object recognition task $\left(t_{(14)}=-0.382, N S\right.$; Fig. 5D).
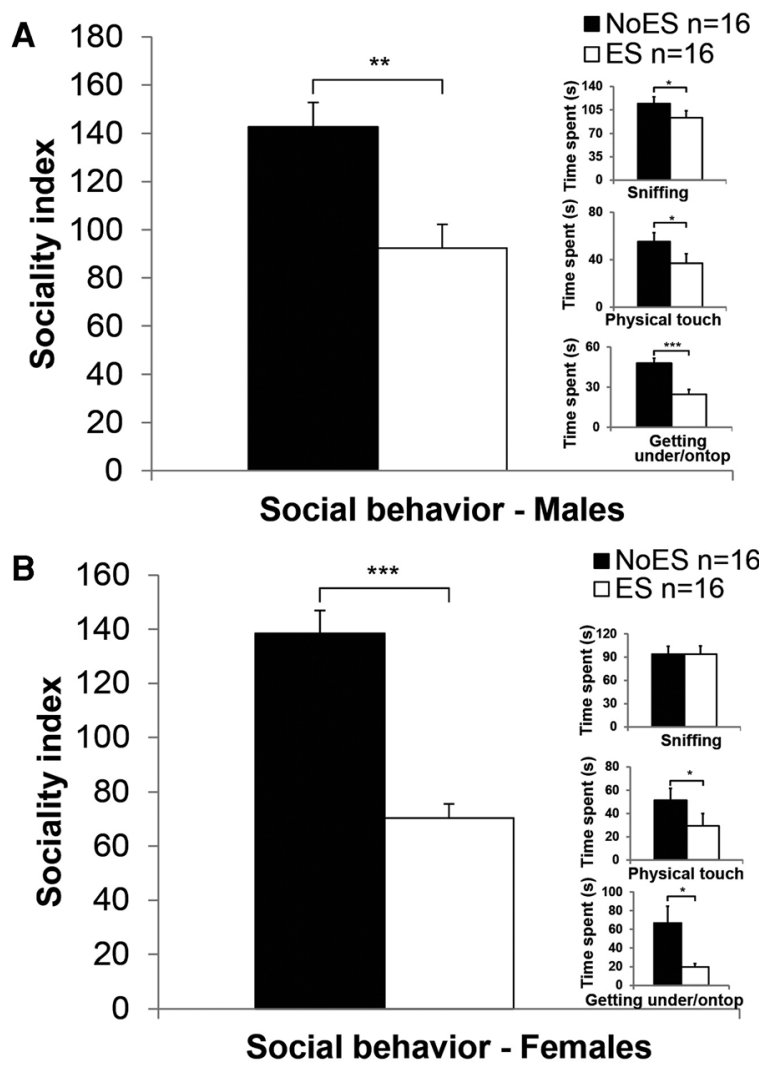

Figure 2. Male and female rats exposed to early stress demonstrate reduced social behavior in the social interaction test. ES males $(A)$ and females $(B)$ demonstrated reduced social behavior on P23 compared with NoES males. (Inset) specific variables from the juvenile social interaction test are provided, demonstrating a significant difference between No ES and ES males on variables such as physical touch and getting under/on top. $\left({ }^{*} P<0.05 ;{ }^{* *} P<0.01 ;{ }^{* * *} P<0.001\right)$. 


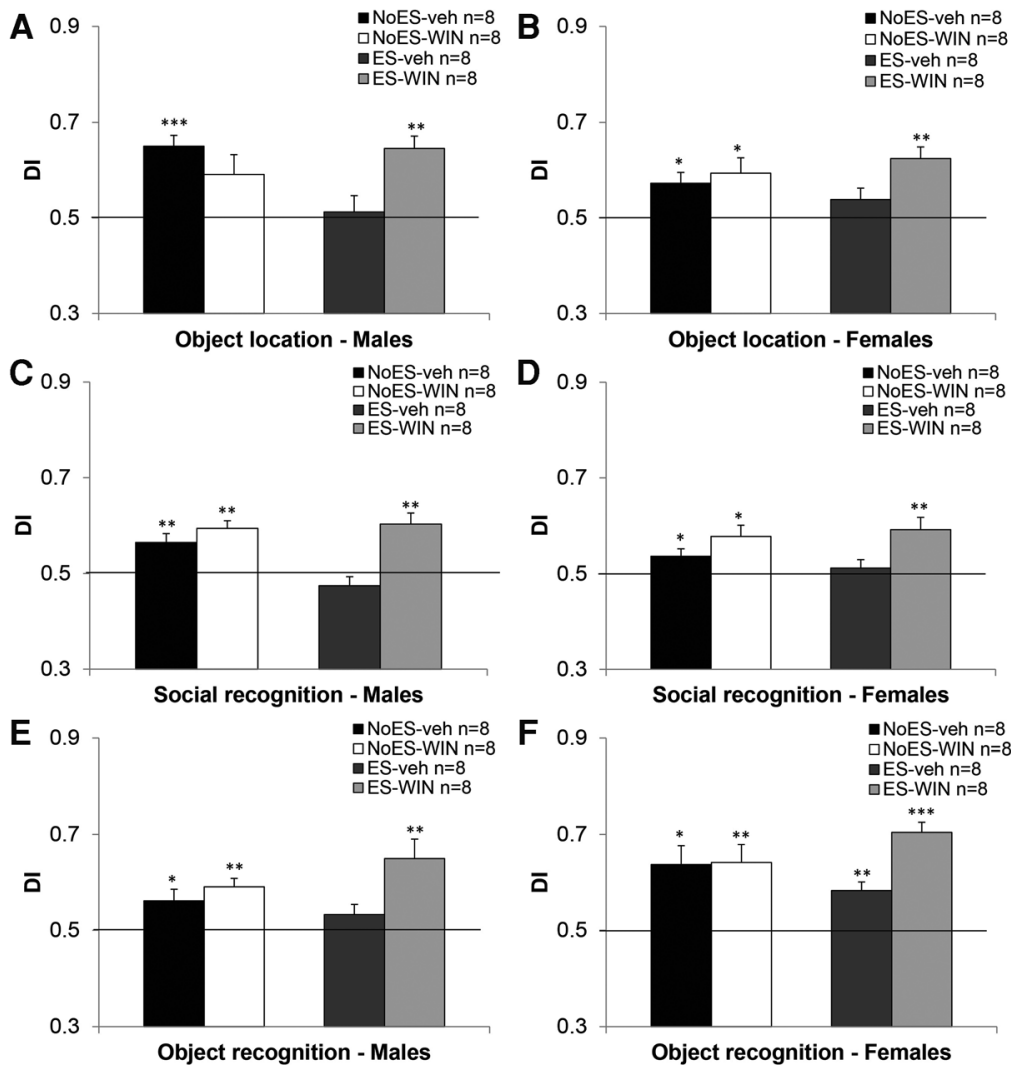

Figure 3. The effects of chronic cannabinoid treatment during the late-adolescence period on shortterm memory in early stressed male and female rats. The ES + veh and NoES + WIN males $(A)$ and the $\mathrm{ES}+$ veh females $(B)$ demonstrated impaired performance in adulthood in a spatial recognition task. The ES + veh males $(C)$ and females $(D)$ demonstrated impaired performance in adulthood in a social recognition task. The ES + veh males $(E)$ demonstrated impaired performance in adulthood in an object recognition task. Whereas all female rats $(F)$ demonstrated intact performance $(* P<0.05$; ${ }^{* *} P<0.01,{ }^{* * *} P<0.001$; indicates a significant difference from the $\left.50 \% \mathrm{DI}\right)$.

One-sample $t$-test revealed a significant difference from the $50 \%$ DI in the ES + veh $\left(t_{(7)}=3.385, P<0.05\right)$, and $\mathrm{ES}+\mathrm{WIN}\left(t_{(7)}=\right.$ 2.447, $P<0.05)$ groups suggesting intact performance. The NoES group performed well in the spatial location task (significantly different from the $50 \% \mathrm{DI} ; \mathrm{M}=0.68, \mathrm{SEM}= \pm 0.02 ; t_{(7)}=$ 2.96, $P<0.05)$.

For the open field task, unpaired $t$-test revealed that the ES + WIN group demonstrated a lower anxiety index than the ES + veh group $\left(t_{(14)}=-6.659, P<0.001 ;\right.$ Fig. 5E).

\section{The effects of exposure to early stress and WIN55,212-2} on $\mathrm{CB} 1$ receptors and GRs in the stress circuit

Previous studies suggest that ES induces elevations in plasma corticosterone levels in young pups (PND 9) (Avishai-Eliner et al. 2001; Ivy et al. 2008). However, these effects seem to disappear in adulthood (Brunson et al. 2005). As previous results from our laboratory and others (Abush and Akirav 2013; Trujillo et al. 2016) suggested that chronic stress exposure had a long-term effect on GR levels in the fear circuit in adulthood, we decided to examine GR levels in the fear circuit in adult rats previously exposed to ES.

CB1r and GRs levels were analyzed using one-way ANOVA in all areas tested. To confirm equal protein loading, different parts of the same membrane ( $\sim 20-50 \mathrm{kDa}$ according to the marker (Bio-Rad)) were rehybridized with antibodies specific for $\beta$-actin. No significant difference in $\beta$-actin levels was observed between groups $(P<0.05)$. In addition, the groups $(P<0.05)$. In addition, the NoES + veh group expressed significantly less GRs than the naïve group $(P<0.05)$. In the BLA in females, a significant group effect was found for CB1r $\left(F_{(3,28)}=5.662, P<0.01\right.$; Fig. $\left.6 \mathrm{~L}\right)$ but not for GRs (Fig. $\left.6 \mathrm{M}\right)$. Post hoc comparison revealed that the NoES + veh group expressed significantly more CB1r than the ES-veh $(P<0.01)$ and ES-WIN $(P<0.05)$ groups.

In the CA1 in males, no significant group effect was found for CB1r or GRs (Fig. 6H,I). In the CA1 in females, a significant group effect was found for CB1r $\left(F_{(3,28)}=3.159, P<0.05\right.$; Fig. $\left.6 \mathrm{~N}\right)$ but not for GRs (Fig. 6O). Post hoc comparison revealed that the $\mathrm{ES}+$ veh female group marginally expressed more CB1r than the Naive and ES-WIN groups $(P<0.065)$. Using the LSD post hoc test revealed that the ES + veh group expressed significantly more CB1r than all groups $(P<0.05)$.

We also examined whether WIN in nonstressed males and females affected the expression of CB1r and GR in the different brain areas. Rats were injected with vehicle or WIN and CB1r and GR levels were measured. Significant differences were found in GR-BLA $\left(F_{(2,23)}=9.342, \quad P<0.0001\right)$ and IL-GR levels $\left(F_{(2,23)}=5.322, P<0.013\right)$ in males, and in CB1r-BLA levels in females $\left(F_{(2,23)}=3.764, P<0.04\right)$. Post hoc comparison revealed a significant reduction in GR-BLA $(P<0.01)$ and IL-GR $(P<0.05)$ levels in NoES-veh males compared with the Naive and NoES-WIN groups. Also, a significant increase was found in CB1r-BLA levels in NoES-veh females compared with the other two groups $(P<0.05)$ (Table 2$)$. 

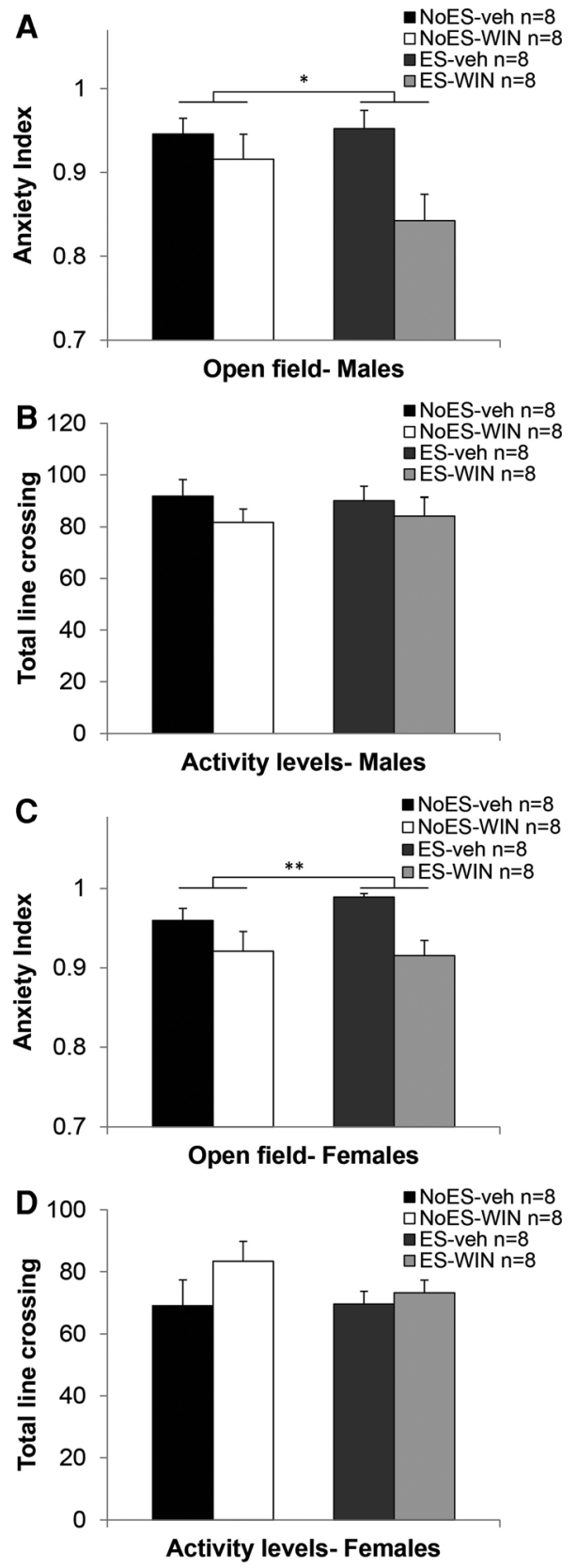

Figure 4. Chronic cannabinoid treatment during the late-adolescence period reduces anxiety-like behavior in an open field test. $(A)$ Males administered with chronic WIN during the late-adolescence period demonstrated less anxiety in the open field test in adulthood compared with vehicle treated males. (B) No significant differences between the male groups in activity levels were found. (C) Females administered with chronic WIN during the late-adolescence period demonstrated less anxiety in the open field test in adulthood compared with vehicle treated females. $(D)$ No significant differences between the female groups in activity levels were found. $\left({ }^{*} P<0.05 ;{ }^{* *} P<\right.$ $0.01)$.

\section{Materials and Methods}

\section{Subjects}

Eight mothers and 64 pups were housed in polypropylene cages $(59 \times 28 \times 20 \mathrm{~cm})$. The mothers arrived pregnant $(14 \mathrm{~d}$ after parturition day) from Harlan, Jerusalem, and Israel. On P20 pups were weaned and caged together ( $n=4$ according to sex) at $22 \pm 2^{\circ} \mathrm{C}$ under 12-h light-dark cycles (lights turned on at 07:00). Food and water were available ad libitum. No more than one male and one female from a litter were used in each experimental condition. The experiments were approved by the University of Haifa Ethics and Animal Care Committee and adequate measures were taken to minimize pain or discomfort.

\section{Early stress model}

The early stress (ES) was the "abusive mother paradigm" (Avishai-Eliner et al. 2001; Raineki et al. 2010) with slight modifications. The dam and her pups were housed in a cage with limited bedding material (1.2-cm layer) from P7 to P14. The no stress mother and her pups were housed in a cage with abundant (5-7 $\mathrm{cm}$ layer) bedding material. Litters were randomly assigned to ES or control (NoES) groups and then randomly assigned to vehicle or WIN55,212-2 groups. The type of bedding material was aspen, except than during the neglect period in which the type of the bedding in the stress condition was sunny chips. Cages were observed three times a day (morning, noon, and afternoon) and during these times we measured maternal behavior (i.e., nursing, cleaning pups, and gathering pups), self-activity (i.e., self-feeding, self-cleaning exploring) and harmful behavior toward pups (step-on, rough handling, isolating pups, and tossing around).

\section{Social behavior test}

After $5 \mathrm{~min}$ of habituation in an open field $(50 \times 50 \times 50 \mathrm{~cm})$, a "partner" rat from the same sex and age was introduced. During the 5-min test, social behaviors (e.g., sniffing the partner, physical contact) and non-social behaviors (e.g., self-grooming, remaining alone) were scored. The tests were videotaped and analyzed by an experimenter blind to the treatments (Segev and Akirav 2011). A sociality index was calculated for each animal that expressed the percent time that each rat spent engaging in social behavior.

\section{Drugs}

WIN55,212-2 (i.p $1.2 \mathrm{mg} / \mathrm{kg}$; Cayman Chemicals) was initially dissolved in DMSO, and further diluted with $1 \%$ Tween 80 and $98 \%$ saline $(0.9 \% \mathrm{NaCl})$. Controls were injected with the vehicle. WIN was administered during P45-P60. WIN55,212-2 dose and injection protocol was based on previous reports (Schneider and Koch 2005, 2007; Abush and Akirav 2012, 2013).

\section{Behavioral testing in adulthood}

1. Open field test. The movements of the rat were recorded for 5 min and analyzed by EthoVision. We measured percent time spent in the center of the open field to measure anxiety and the total line crossings for activity levels. As rats in all groups spent most of their time in the peripheral areas (suggesting a celling effect of high anxiety in all groups), we used a more sensitive anxiety index based on Avital and Richer-Levin (2005). The anxiety index was calculated based on the ratio between line crossings in the peripheral area and the total line crossings. The open-field arena was thoroughly cleaned between trials.

2. Object location memory test ${ }^{3}$. See Abush and Akirav (2012). Two identical objects $(10 \times 8 \times 7 \mathrm{~cm})$ were located in the openfield, under dim light, $10 \mathrm{~cm}$ from the walls. The rats were habituated to the open field 10 min every day for $4 \mathrm{~d}$ without objects. In the sample phase, each rat was exposed to the objects for $5 \mathrm{~min}$. In the test phase, given $30 \mathrm{~min}$ after the sample trial, one object was moved to a new location and the time

${ }^{3}$ The order of the object location and object recognition tests was counterbalanced. 
A

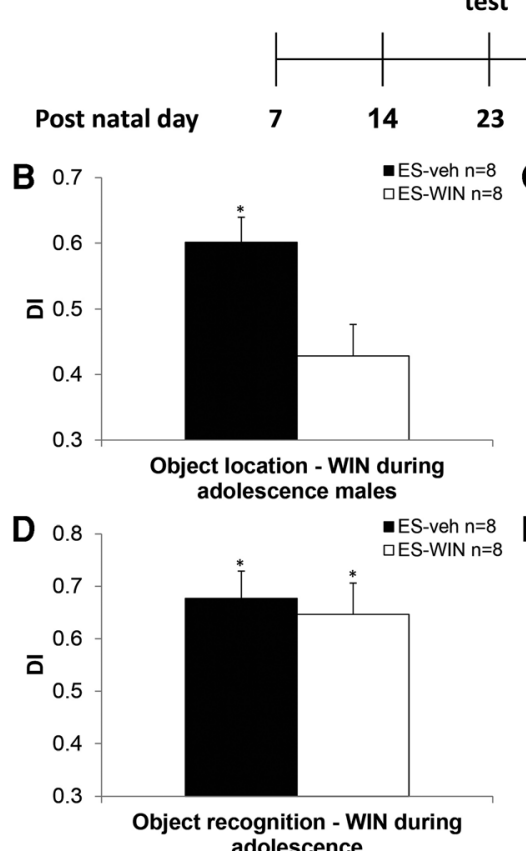

adolescence
ES/NoES $\begin{gathered}\text { Social } \\ \text { test }\end{gathered} \quad$ Veh/WIN
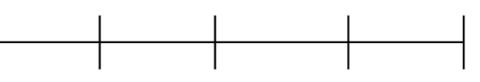

$30 \quad 45$

$45 \quad 75$

$75 \quad 82$

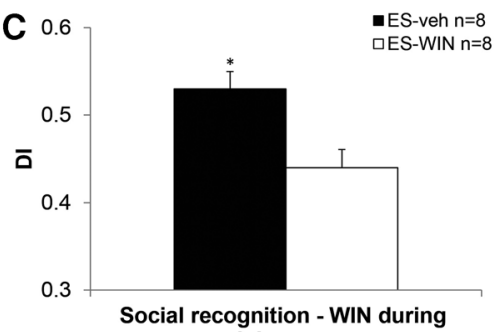
adolescence

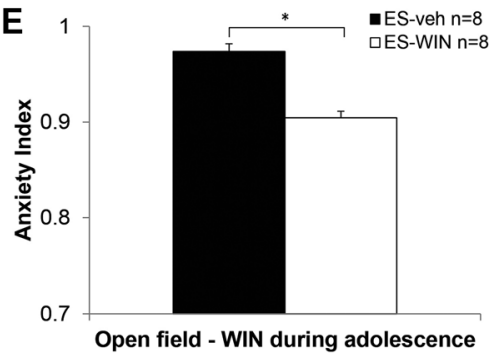

Figure 5. The effects of chronic cannabinoid treatment during the adolescence period on short-term memory and anxiety in early stressed males. $(A)$ Experimental design: The dam and her pups were housed in a cage with limited (ES) bedding material from P7 to P14. On day 23, pups were exposed to a social interaction test to verify that early stress exposure results in impaired social behavior. During the adolescence period (P30-P45) rats received 14 injections of vehicle (veh) or the CB1/2 agonist WIN. On P75 rats were taken to neurocognitive tests (object location, object recognition, and social recognition) and to the open field for an anxiety test (P75-79: habituation to the memory tests arena; P80: object recognition; P81: object location; P82 social recognition; P83 open field). (B) ES WIN-treated adolescent males demonstrated impaired performance in adulthood in a spatial recognition task compared to ES vehicle-treated males. (C) ES WIN-treated adolescent males demonstrated impaired performance in adulthood in a social recognition task compared with ES vehicle-treated males. $(D)$ No difference in performance in the object recognition task was observed. (E) ES WIN-treated adolescent males demonstrated less anxiety in an open field test compared with vehicle-treated rats in adulthood. $\left({ }^{*} P<0.05\right)$.

spent exploring the objects at the old and new locations were recorded for $5 \mathrm{~min}$. Recorded data was analyzed by two judges blind to experimental conditions and inter-rater reliability was assured.

Exploration was defined as when the subject sniffed/whisked/ looked at the object from no more than $2 \mathrm{~cm}$ away. An exploration index calculated for each animal is expressed as $T_{\mathrm{N}} /\left(T_{\mathrm{N}}+T_{\mathrm{F}}\right)$ $\left(T_{\mathrm{F}}=\right.$ time spent exploring the object in the familiar location; $T_{\mathrm{N}}=$ time spent exploring the object in the novel location). Intact spatial recognition memory in the test phase is reflected in an exploration score higher than 0.5 , which implies greater exploration of the object in the novel location.

3. Novel object recognition memory test. In the sample phase, each rat was placed in the arena and exposed to two identical objects for $5 \mathrm{~min}$. In the test phase, the rat was presented with one of the objects from the sample trial and with a novel object for $5 \mathrm{~min}$. The familiar and novel objects were counterbalanced during the sample and test phases. The rest of the parameters were identical to the object location task described above (Abush and Akirav 2012).

4. Social recognition test. In the sample phase, each rat was placed in the arena and exposed to two juvenile rats from the same sex for $5 \mathrm{~min}$. In the test phase, the experimental rat was presented with the juvenile it had previously investigated

and a novel juvenile for $5 \mathrm{~min}$. The duration of investigatory behavior of the experimental rat toward each juvenile was recorded and measured by two trained observers blind to the animals' treatment (Segev and Akirav 2011). The rest of the parameters were identical to the object location task described above.

\section{Western blotting}

Rats were sacrificed and brain tissues of the infralimbic (IL) PFC, BLA, and CA1 were collected and homogenized in buffer. Protein levels were determined by the bicinchoninic acid (BCA) Protein Assay Kit (Pierce) according to the manufacturer's protocol. The samples were then diluted in SDS sample buffer, boiled $\left(100^{\circ} \mathrm{C}\right)$ for $5 \mathrm{~min}$ and stored at $-80^{\circ} \mathrm{C}$. Aliquots were subjected to SDS-PAGE (10\% polyacrylamide) and immunublot analysis. Blots were incubated with the GR/CB1 antibody overnight at $4^{\circ} \mathrm{C}$ (1:100, Pierce Antibodies) followed by washing and $1 \mathrm{~h}$ incubation with an HRP-linked secondary antibody at room temperature (goat anti-rabbit IgG; Jackson ImmunoResearch Laboratories, 1:10,000). Blots were visualized by enhanced chemiluminescence with ECL (Biological Industries) and quantified with an XRS charge-coupled device camera (Bio-Rad Laboratories) and Quantity One software. All protein samples were standardized with $\beta$-actin (1: 5000, polyclonal goat antibody; Santa Cruz Biotechnology, USA).

\section{Statistical analysis}

The results are expressed as means \pm SEM. For statistical analysis, two-way ANOVA, one-way ANOVA, and $t$-tests are used. Post hoc comparisons are made using Tukey.

\section{Discussion}

Experiences of severe trauma during childhood are thought to be risk factors for developing mental disorders, such as anxiety and mood disorders, later in life. This study demonstrates that exposure to ES can have long-term detrimental effects on emotionality and behavior. Importantly, we demonstrate that cannabinoid treatment during late adolescence can reverse the long-term effects of early stress on emotional behavior and short-term memory in male and female rats.

Furthermore, exposure to ES induced up-regulation in PFC-GRs and CA1-CB1r in females and WIN normalized this effect. In males, WIN normalized the ES-induced up-regulation in PFC-GR and down-regulation in BLA-CB1r.

Our findings suggest that there is a crucial role of the endocannabinoid system in the effects of early life stress on behavior at adulthood. In addition: (i) the late-adolescence period, as opposed to the adolescence period, is a possible neurodevelopment window for chronic treatment with cannabinoids, (ii) CB1r and GRs in the brain's stress circuit are involved in the therapeutic effects of WIN, and (iii) there are sex differences in the mechanisms underlying coping with ES. 
A
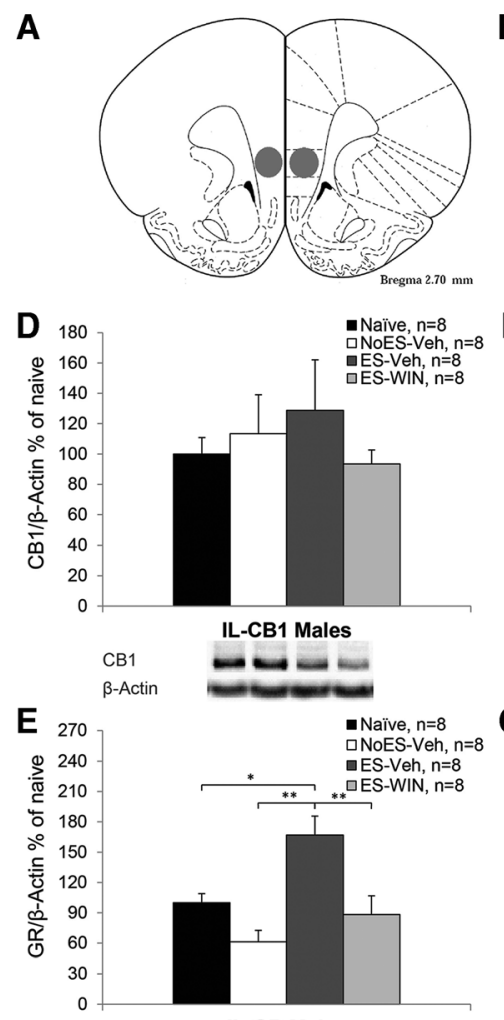

IL-GR Males
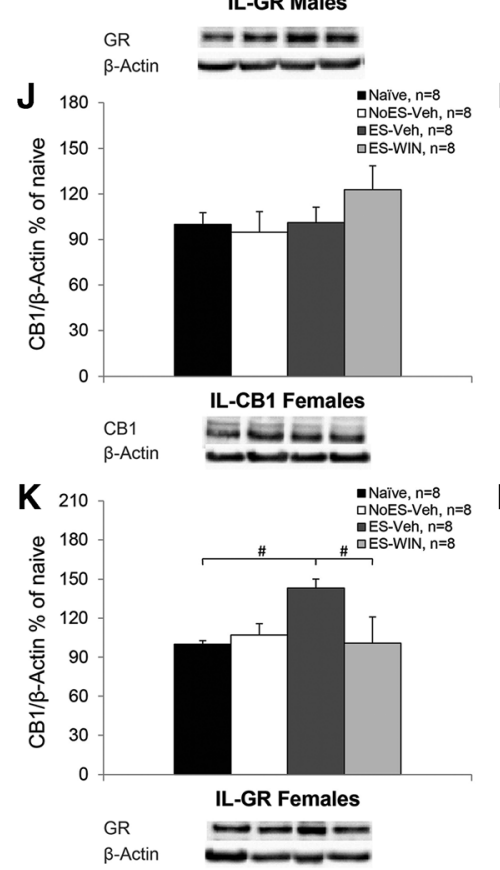

B
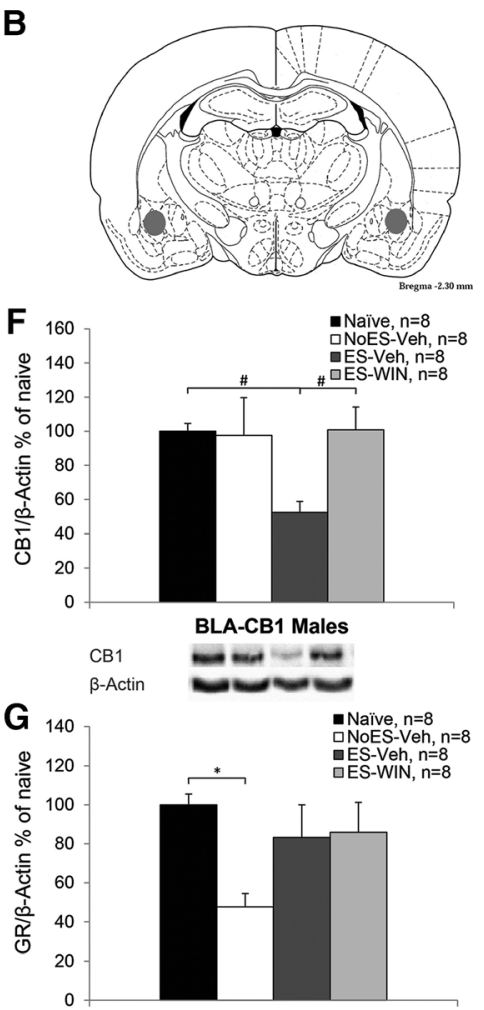

BLA-GR Males
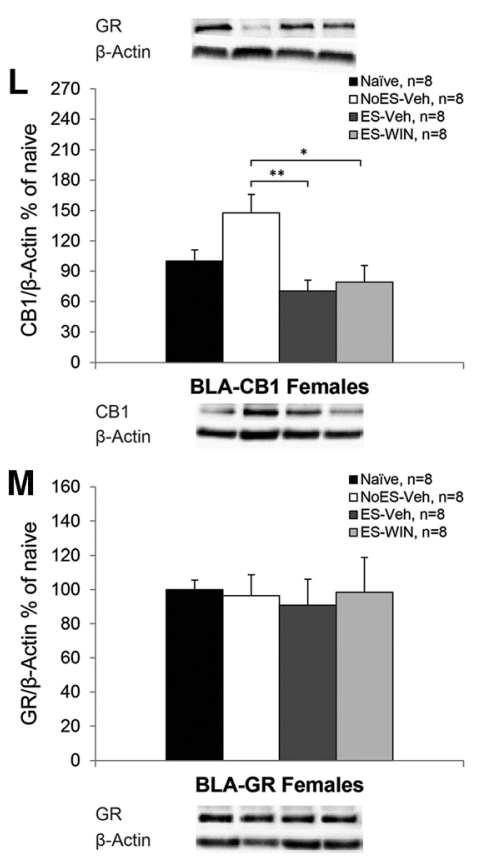

C
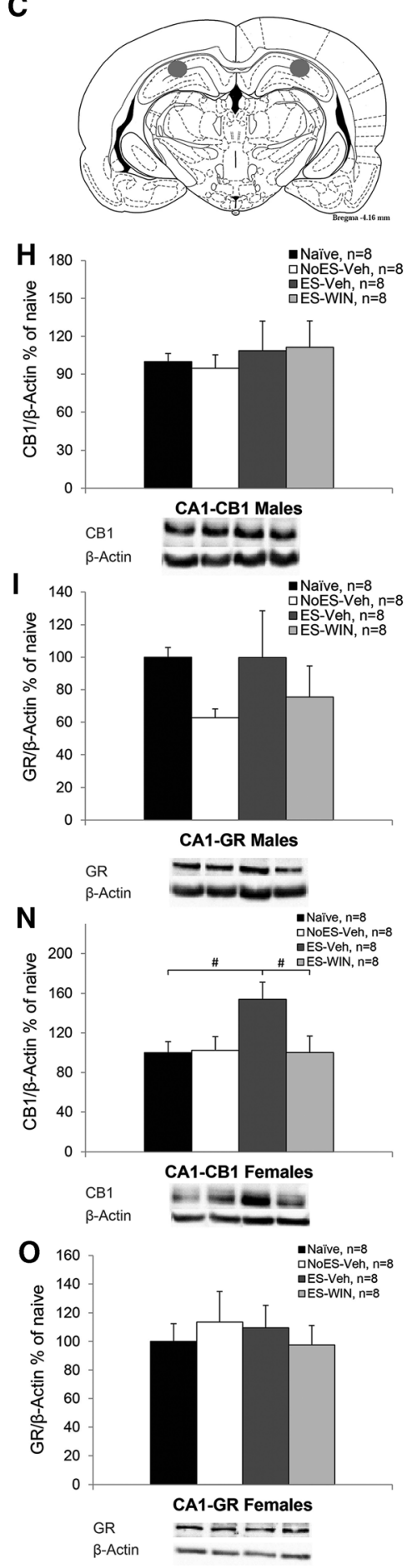

Figure 6. The effects of exposure to early stress and WIN55,212-2 on CB1 receptors and GRs in the stress circuit. ( $A$ ) Brain sites from where the tissue samples were extracted. The IL-PFC was obtained by punches ( $1 \mathrm{~mm}$-diameter) bilaterally. The numbers refer to the distance from Bregma (based on Paxinos and Watson 2006). (B) The BLA was obtained by punches (1-mm diameter) bilaterally. (C) The CA1 was obtained by punches (1-mm diameter) bilaterally. $\left({ }^{*} P<0.05 ;{ }^{* *} P<0.01\right)$. (D) In the IL-PFC of males, no significant differences in CB1 $r$ were observed between the groups. ( $E$ ) In the IL-PFC of males, the ES + veh group expressed significantly more GR than all groups. $(F)$ In the BLA of males, the ES + veh group expressed significantly less CB1 $r$ than all groups. $(G)$ In the BLA of males, the NoES + veh group expressed significantly less GR than the naïve group. $(H)$ In the CA1 of males, no significant differences in CB1 r were observed between the groups. (I) In the CA1 of males, no significant differences were observed in GR between the groups. $(J)$ In the IL-PFC of females, no significant differences in CB1r were observed between the groups. $(K)$ In the IL-PFC of females, the ES + veh group expressed significantly more GR than all groups. $(L)$ In the BLA of females, the NoES + veh group expressed significantly more CB1 $r$ than the ES groups. ( $M$ ) In the BLA of females, no significant differences in GR were observed between the groups. $(N)$ In the CA1 of females, the ES + veh group expressed significantly more CB1r than all groups. (O) In the CA1 of females, no significant differences were observed in GR between the groups. (Lower panel) Representative bands for the expression of GR/CB1 $r$ and $\beta$-actin. 
Table 2. The effects of WIN55,212-2 injections on GR and CB1 receptor expression in nonstressed rats

\begin{tabular}{|c|c|c|c|c|c|c|c|}
\hline & & \multicolumn{3}{|c|}{ Males } & \multicolumn{3}{|c|}{ Females } \\
\hline & & Naïve & NoES + Veh & NoES + WIN & Naïve & NoES + Veh & NoES + WIN \\
\hline \multirow[t]{2}{*}{ BLA } & CB1 & $100 \pm 4.54 n=8$ & $97.58 \pm 22.12 n=8$ & $90.61 \pm 13.12 n=8$ & $100 \pm 11.02 n=8$ & $159.18 \pm 19.77 n=8^{*}$ & $96.3 \pm 13.77 n=8$ \\
\hline & GR & $100 \pm 5.51 n=8$ & $47.68 \pm 6.8 n=8^{* *}$ & $92.05 \pm 13.37 n=8$ & $100 \pm 5.53 n=8$ & $94.83 \pm 12.05 n=8$ & $98.83 \pm 11.07 n=8$ \\
\hline \multirow[t]{2}{*}{ CA1 } & CB1 & $100 \pm 6.37 n=8$ & $94.66 \pm 10.71 n=8$ & $139.79 \pm 19.93 n=8$ & $100 \pm 11.08 n=8$ & $100.45 \pm 13.62 n=8$ & $95.43 \pm 16.89 n=8$ \\
\hline & GR & $100 \pm 5.95 n=8$ & $62.74 \pm 5.48 n=8$ & $90.27 \pm 20.65 n=8$ & $100 \pm 12.44 n=8$ & $96.29 \pm 17.98 n=8$ & $140.46 \pm 19.36 n=8$ \\
\hline \multirow[t]{2}{*}{ IL } & CB1 & $100 \pm 10.86 n=8$ & $113.37 \pm 25.7 n=8$ & $103.07 \pm 18.07 n=8$ & $100 \pm 7.71 n=8$ & $87.8 \pm 12.47 n=8$ & $114.07 \pm 10.43 n=8$ \\
\hline & GR & $100 \pm 8.86 n=8$ & $61.36 \pm 11.27 n=8^{*}$ & $98.09 \pm 13.14 n=8$ & $100 \pm 2.75 n=8$ & $97.48 \pm 7.88 n=8$ & $111.35 \pm 7.69 n=8$ \\
\hline
\end{tabular}

In males, a significant reduction in GR-BLA and IL-GR levels in the NoES-veh group versus the other groups. In females, a significant increase in CB1 r-BLA levels in the NoES-veh group compared with the other groups $\left({ }^{*} P<0.05 ;{ }^{* *} P<0.01\right)$.

\section{The effects of exposure to early stress on cognition and anxiety}

Male rats exposed to ES exhibited impaired performance in shortterm memory in adulthood: in the spatial location, social recognition, and novel object recognition tasks. ES females also exhibited impaired performance in the spatial location and social recognition tasks, but not in the novel object recognition task.

ES is associated with abnormal cognitive function. Llorente et al. (2012) described an impaired performance in the PFCdependent novel object task among early-stress rats (maternal separation of $24 \mathrm{~h}$ during P9), with males being most clearly affected. ES was also found to impair spatial hippocampal-dependent learning and memory; Brunson et al. (2005), showed that neonatal rats exposed to decreased bedding layer (P2-P9) exhibited impaired spatial performance in adulthood in the Morris water maze. As for the social task, it has been suggested that social behavior deficits in infancy could serve as an early marker for later psychopathology (Raineki et al. 2012). ES males and females in our study showed impaired social behavior on P23 and demonstrated stable social impairment as observed in the social recognition task on P97. Previous studies also showed social impairment after ES (Roth and Sullivan 2005; Lukas et al. 2011).

WIN administered during late-adolescence prevented the stress-induced impairments in short-term memory in males and females and reduced anxiety levels. Interestingly, male and female rats seemed to be affected by the chronic injections themselves, as the nonstressed vehicle group showed high levels of anxiety in adulthood, demonstrating a possible ceiling effect.

When ES males were injected with the agonist WIN during adolescence, a different picture emerged. In this group, WIN did not prevent the effects of ES on performance in the spatial and social tasks. No effects of ES were found in the object recognition task. Yet, WIN administered during adolescence reduced anxiety in adulthood as observed in the late-adolescent WIN injected rats. This suggests that the preventing effects of WIN on short-term memory impairment in the late-adolescent period could not be merely explained through the anxiolytic effects of the agonist.

These findings corroborate with previous studies suggesting that exposure to cannabinoids in adolescent rodents leads to dysregulation of emotional processes and impairments in learning and memory in adulthood (for review, see Rubino and Parolaro 2016).

\section{Alterations in CBlr and GRs in the stress circuit}

Rats exposed to ES demonstrated alterations in the expression of CB1r and GRs in brain areas critical for learning and emotion. In males, ES down-regulated BLA-CB1r and up-regulated IL-GRs and WIN normalized these effects. In females, ES up-regulated CA1-CB1r and up-regulated IL-GRs and WIN normalized these ef- fects. These findings are in line with previous studies suggesting that corticolimbic endocannabinoid signaling is capable of mediating, at least in part, interactions between stress exposure and development (Marco et al. 2009; Llorente-Berzal et al. 2011).

Nonstressed males and females injected with vehicle demonstrated down-regulation of BLA-GRs and up-regulation of BLA$\mathrm{CB} 1 \mathrm{r}$, respectively, further suggesting that they were affected by the chronic injections.

Previous studies have shown that CB1r expression increased in the ventral striatum while it was decreased in the frontal cortex in maternally separated rats (P1-14) (Romano-Lopez et al. 2012). Maternal deprivation, $24 \mathrm{~h}$ at P9, induced in adolescent males and females a significant reduction in CB1 receptor expression in the frontal cortex (Marco et al. 2013) and decreased hippocampal GR only in males (Llorente et al. 2012). However, the maternal deprivation model has been shown to have different effects on behavior and emotionality than the early neglect model we used (Llorente et al. 2012; Marco et al. 2013).

Cognitive impairment is a major cause of disability in schizophrenia, depression, and anxiety disorders (Porter et al. 2003). Working memory and other "top-down" cognitive functions have long been known to depend on the PFC. The PFC is vulnerable to stress (McEwen and Gianaros 2011) and is affected by decreased estrogen levels in women (Shanmugan and Epperson 2014).

One possible explanation for the observed effects in our study is that ES resulted in a blunted HPA response (i.e., decreased the release of glucocorticoids as often found in PTSD) which led to the long-term effect of IL-GRs up-regulation. The PFC regulates the activity of the HPA axis and the IL specifically excites HPA activation following stress. This could suggest that the impairing effects of early stress on short-term memory are associated with IL-GRs up-regulation. Despite sex differences in many parameters of HPA system function, reports of sex differences in GRs are few (Catalani et al. 2011).

The agonist WIN reversed the impairment in short-term/ working memory as well as IL-GRs up-regulation. Indeed, bidirectional and functional relationships between glucocorticoids and the endocannabinoid system have been demonstrated. Specifically, stress is known to produce rapid changes in endocannabinoid signaling in stress-responsive brain regions. In turn, the endocannabinoid system plays an important role in the downregulation and habituation of HPA axis activity in response to stress. Glucocorticoids also recruit the endocannabinoid system to exert rapid negative feedback control of the HPA axis during stress (Patel et al. 2004; Rademacher et al. 2008; Steiner and Wotjak 2008; Hill et al. 2011; Hill and Tasker 2012; Akirav 2013).

Childhood maltreatment is associated with HPA axis dysregulation and diurnal cortisol profiles, as well as stress reactivity. Animal studies suggest that timing of early adversity is a crucial factor in neuroendocrinological outcomes due to the highly plastic nature of the HPA axis early in life (Tarullo and Gunnar 2006). 
By the end of the first week of life and continuing into the second one, young rats display a "stress hyporesponsive period" (SHRP). This mechanism flattens deleterious fluctuations in glucocorticoids, limiting their adverse effects, and hence, defends neonates against adverse programming of the HPA system. On the other hand, if corticosterone levels in the mother are increased by environmental events, it reaches the pups and is able to influence the maturation of the HPA axis of the developing rat. Even if circulating corticosterone during development is very low, it may produce a significant activation of the GR because the effective (free) corticosterone concentration is high by virtue of low levels of corticosteroid binding globulin during the SHRP.

Adolescence, as opposed to adulthood, is a period of high neural plasticity but is also high in susceptibility to disturbances that might contribute to dysregulation of the HPA axis and endocannabinoid signaling in the corticolimbic circuit (Buwalda et al. 2011). Moreover, it has been suggested that exogenous cannabinoids during adolescent maturation may result in long-term effects on HPA function which might affect subsequent stress reactivity, cognitive functioning, and emotionally relevant behavior (Viveros et al. 2005; Realini et al. 2009, 2011; Rubino et al. 2009; Buwalda et al. 2011; Campolongo et al. 2011; LlorenteBerzal et al. 2011). Hence, the reversal effects observed during the late-adolescent period, but not during adolescence, could be the result of a developing CNS that is more sensitive to environmental influences, such as stress and drugs, than the adult CNS.

\section{Summary}

Taken together, our results support the notion that exposure of rodents to stress in early life is associated with changes in the sensitivity of the HPA axis, social behavior, and learning and memory.

Except for the object recognition task, ES caused similar cognitive deficits and enhanced anxiety in males and females. Furthermore, the cannabinoid agonist had a protective effect against the deleterious consequences of ES in both males and females when administered during late adolescence.

While cannabinoid exposure during adolescence might have pervasive and negative effects on cognition, here we argue that it might have protective effects against the deleterious consequences of early stress when administered at late adolescence. The differential effect of cannabinoids administered during adolescence versus late adolescence could have some important implications for age of onset with respect to cannabinoid therapeutics.

The study suggests the involvement of CB1r and GRs in the brain's stress circuit in the therapeutic effects of WIN; yet, further studies are required to fully understand the underlying mechanisms.

\section{Acknowledgments}

This research was supported by The Israel Science Foundation (grant no. 572/12 to I.A.) (URL:http://www.isf.org.il/).

\section{References}

Abush H, Akirav I. 2012. Short-and long-term cognitive effects of chronic cannabinoids administration in late-adolescence rats. PLoS One 7: e31731.

Abush H, Akirav I. 2013. Cannabinoids ameliorate impairments induced by chronic stress to synaptic plasticity and short-term memory. Neuropsychopharmacology 38: 1521-1534.

Ahima RS, Harlan RE. 1990. Charting of type II glucocorticoid receptor-like immunoreactivity in the rat central nervous system. Neuroscience 39: $579-604$

Akirav I. 2013. Cannabinoids and glucocorticoids modulate emotional memory after stress. Neurosci Biobehav Rev 37: 2554-2563.

Avishai-Eliner S, Gilles EE, Eghbal-Ahmadi M, Bar-El Y, Baram TZ. 2001. Altered regulation of gene and protein expression of hypothalamic- pituitary-adrenal axis components in an immature rat model of chronic stress. J Neuroendocrinol 13: 799-807.

Avital A, Richter-Levin G. 2005. Exposure to juvenile stress exacerbates the behavioural consequences of exposure to stress in the adult rat. Int $J$ Neuropsychopharmacol 8: 163-173.

Biscaia M, Fernández B, Higuera-Matas A, Miguéns M, Viveros M-P, García-Lecumberri C, Ambrosio E. 2008. Sex-dependent effects of periadolescent exposure to the cannabinoid agonist CP-55,940 on morphine self-administration behaviour and the endogenous opioid system. Neuropharmacology 54: 863-873.

Bortolato M, Mangieri RA, Fu J, Kim JH, Arguello O, Duranti A, Tontini A, Mor M, Tarzia G, Piomelli D. 2007. Antidepressant-like activity of the fatty acid amide hydrolase inhibitor URB597 in a rat model of chronic mild stress. Biol Psychiatry 62: 1103-1110.

Brunson KL, Kramár E, Lin B, Chen Y, Colgin LL, Yanagihara TK, Lynch G, Baram TZ. 2005. Mechanisms of late-onset cognitive decline after early-life stress. J Neurosci 25: 9328-9338.

Buwalda B, Geerdink M, Vidal J, Koolhaas JM. 2011. Social behavior and social stress in adolescence: a focus on animal models. Neurosci Biobehav Rev 35: 1713-1721.

Campolongo P, Trezza V, Ratano P, Palmery M, Cuomo V. 2011. Developmental consequences of perinatal cannabis exposure: behavioral and neuroendocrine effects in adult rodents. Psychopharmacology (Berl) 214: 5-15.

Catalani A, Alemà GS, Cinque C, Zuena AR, Casolini P. 2011. Maternal corticosterone effects on hypothalamus-pituitary-adrenal axis regulation and behavior of the offspring in rodents. Neurosci Biobehav Rev 35: 1502-1517.

Champagne DL, Bagot RC, van Hasselt F, Ramakers G, Meaney MJ, De Kloet ER, Joëls M, Krugers H. 2008. Maternal care and hippocampal plasticity: evidence for experience-dependent structural plasticity, altered synaptic functioning, and differential responsiveness to glucocorticoids and stress. J Neurosci 28: 6037-6045.

Egerton A, Allison C, Brett RR, Pratt JA. 2006. Cannabinoids and prefrontal cortical function: insights from preclinical studies. Neurosci Biobehav Rev 30: 680-695.

Ganon-Elazar E, Akirav I. 2012. Cannabinoids prevent the development of behavioral and endocrine alterations in a rat model of intense stress. Neuropsychopharmacology 37: 456-466.

Ganon-Elazar E, Akirav I. 2013. Cannabinoids and traumatic stress modulation of contextual fear extinction and GR expression in the amygdala-hippocampal-prefrontal circuit. Psychoneuroendocrinology 38: $1675-1687$.

Glaser D. 2000. Child abuse and neglect and the brain-a review. J Child Psychol Psychiatry 41: 97-116.

Herkenham M, Lynn AB, Little MD, Johnson MR, Melvin LS, De Costa BR, Rice KC. 1990. Cannabinoid receptor localization in brain. Proc Natl Acad Sci 87: 1932-1936.

Hill MN, Gorzalka BB. 2009. The endocannabinoid system and the treatment of mood and anxiety disorders. Curr Drug Targets 8: 451-458.

Hill MN, Tasker JG. 2012. Endocannabinoid signaling, glucocorticoid-mediated negative feedback, and regulation of the hypothalamic-pituitary-adrenal axis. Neuroscience 204: 5-16.

Hill MN, McLaughlin RJ, Pan B, Fitzgerald ML, Roberts CJ, Lee TT-Y, Karatsoreos IN, Mackie K, Viau V, Pickel VM. 2011. Recruitment of prefrontal cortical endocannabinoid signaling by glucocorticoids contributes to termination of the stress response. J Neurosci 31: 10506-10515.

Ivy AS, Brunson KL, Sandman C, Baram TZ. 2008. Dysfunctional nurturing behavior in rat dams with limited access to nesting material: a clinically relevant model for early-life stress. Neuroscience 154: 1132-1142.

Jager G, Ramsey NF. 2008. Long-term consequences of adolescent cannabis exposure on the development of cognition, brain structure and function: an overview of animal and human research. Curr Drug Abuse Rev 1: $114-123$.

Katona I, Rancz EA, Acsády L, Ledent C, Mackie K, Hájos N, Freund TF 2001. Distribution of CB1 cannabinoid receptors in the amygdala and their role in the control of GABAergic transmission. J Neurosci 21: $9506-9518$.

Korem N, Akirav I. 2014. Cannabinoids prevent the effects of a footshock followed by situational reminders on emotional processing. Neuropsychopharmacology 39: 2709-2722.

Levine S. 2005. Developmental determinants of sensitivity and resistance to stress. Psychoneuroendocrinology 30: 939-946.

Lichtman AH, Varvel SA, Martin BR. 2002. Endocannabinoids in cognition and dependence. Prostaglandins Leukot Essent Fatty Acids 66: 269-285.

Llorente-Berzal A, Fuentes S, Gagliano H, López-Gallardo M, Armario A, Viveros M.-P, Nadal R. 2011. Sex-dependent effects of maternal deprivation and adolescent cannabinoid treatment on adult rat behaviour. Addict Biol 16: 624-637.

Llorente R, Villa P, Marco EM, Viveros MP. 2012. Analyzing the effects of a single episode of neonatal maternal deprivation on metabolite profiles 
in rat brain: a proton nuclear magnetic resonance spectroscopy study. Neuroscience 201: 12-19.

López-Gallardo M, Lopez-Rodriguez AB, Llorente-Berzal A, Rotllant D, Mackie K, Armario A, Nadal R, Viveros M.-P. 2012. Maternal deprivation and adolescent cannabinoid exposure impact hippocampal astrocytes, CB1 receptors and brain-derived neurotrophic factor in a sexually dimorphic fashion. Neuroscience 204: 90-103.

Lukas M, Bredewold R, Landgraf R, Neumann ID, Veenema AH. 2011. Early life stress impairs social recognition due to a blunted response of vasopressin release within the septum of adult male rats. Psychoneuroendocrinology 36: 843-853.

Lupien SJ, McEwen BS, Gunnar MR, Heim C. 2009. Effects of stress throughout the lifespan on the brain, behaviour and cognition. Nat Rev Neurosci 10: 434-445.

Macrì S, Laviola G. 2004. Single episode of maternal deprivation and adult depressive profile in mice: interaction with cannabinoid exposure during adolescence. Behav Brain Res 154: 231-238.

Marco EM, Rubino T, Adriani W, Viveros M.-P, Parolaro D, Laviola G. 2009. Long-term consequences of URB597 administration during adolescence on cannabinoid CB1 receptor binding in brain areas. Brain Res 1257: 25-31.

Marco EM, Valero M, de la Serna O, Aisa B, Borcel E, Ramirez MJ, Viveros M.-P. 2013. Maternal deprivation effects on brain plasticity and recognition memory in adolescent male and female rats. Neuropharmacology 68: 223-231.

Maren S, De Oca B, Fanselow MS. 1994. Sex differences in hippocampal long-term potentiation (LTP) and Pavlovian fear conditioning in rats: positive correlation between LTP and contextual learning. Brain Res 661: $25-34$.

Marsicano G, Kuner R. 2008. Anatomical distribution of receptors, ligands and enzymes in the brain and in the spinal cord: circuitries and neurochemistry. In Cannabinoids in the brain (ed. Köfalvi A), pp. 161-201. Springer.

Marsicano G, Wotjak CT, Azad SC, Bisogno T, Rammes G, Cascio MG, Hermann H, Tang J, Hofmann C, Zieglgansberger W. 2002. The endogenous cannabinoid system controls extinction of aversive memories. Nature 418: 530-534.

McEwen BS, Gianaro PJ. 2011. Stress-and allostasis-induced brain plasticity. Annu Rev Med 62: 431

McLaughlin RJ, Hill MN, Morrish AC, Gorzalka BB. 2007. Local enhancement of cannabinoid CB1 receptor signalling in the dorsal hippocampus elicits an antidepressant-like effect. Behav Pharmacol 18: 431-438.

Moreira FA, Wotjak CT. 2010. Cannabinoids and anxiety. In Behavioral neurobiology of anxiety and its treatment, pp. 429-450. Springer.

O'Shea M, Singh ME, McGregor IS, Mallet PE. 2004. Chronic cannabinoid exposure produces lasting memory impairment and increased anxiety in adolescent but not adult rats. J Psychopharmacol 18: 502-508.

O'Shea M, McGregor IS, Mallet PE. 2006. Repeated cannabinoid exposure during perinatal, adolescent or early adult ages produces similar longlasting deficits in object recognition and reduced social interaction in rats. J Psychopharmacol 20: 611-621.

Patel S, Roelke CT, Rademacher DJ, Cullinan WE, Hillard CJ. 2004. Endocannabinoid signaling negatively modulates stress-induced activation of the hypothalamic-pituitary-adrenal axis. Endocrinology 145: $5431-5438$.

Paxinos G, Franklin KB. 2006. The rat brain in stereotaxic coordinates, 6th ed. Gulf Professional Publishing, Houston, TX.

Porter RJ, Gallagher P, Thompson JM, Young AH. 2003. Neurocognitive impairment in drug-free patients with major depressive disorder. Br J Psychiatry 182: 214-220.

Quinn HR, Matsumoto I, Callaghan PD, Long LE, Arnold JC, Gunasekaran N, Thompson MR, Dawson B, Mallet PE, Kashem MA. 2008. Adolescent rats find repeated $\Delta 9$-THC less aversive than adult rats but display greater residual cognitive deficits and changes in hippocampal protein expression following exposure. Neuropsychopharmacology 33: 1113-1126.

Rademacher DJ, Meier SE, Shi L, Ho W-SV, Jarrahian A, Hillard CJ. 2008. Effects of acute and repeated restraint stress on endocannabinoid content in the amygdala, ventral striatum, and medial prefrontal cortex in mice. Neuropharmacology 54: 108-116.

Raineki C, Moriceau S, Sullivan RM. 2010. Developing a neurobehavioral animal model of infant attachment to an abusive caregiver. Biol Psychiatry 67: 1137-1145.

Raineki C, Cortés MR, Belnoue L, Sullivan RM. 2012. Effects of early-life abuse differ across development: infant social behavior deficits are followed by adolescent depressive-like behaviors mediated by the amygdala. J Neurosci 32: 7758-7765.

Realini N, Rubino T, Parolaro D. 2009. Neurobiological alterations at adult age triggered by adolescent exposure to cannabinoids. Pharmacol Res 60: $132-138$.
Realini N, Vigano D, Guidali C, Zamberletti E, Rubino T, Parolaro D. 2011. Chronic URB597 treatment at adulthood reverted most depressive-like symptoms induced by adolescent exposure to THC in female rats. Neuropharmacology 60: $235-243$.

Riedel G, Davies SN. 2005. Cannabinoid function in learning, memory and plasticity. Handb Exp Pharmacol 168: 445-777.

Romano-Lopez A, Mendez-Diaz M, Ruiz-Contreras AE, Carrisoza R, Prospero-Garcia O. 2012. Maternal separation and proclivity for ethanol intake: a potential role of the endocannabinoid system in rats. Neuroscience 223: 296-304.

Roth TL, Sullivan RM. 2005. Memory of early maltreatment: neonatal behavioral and neural correlates of maternal maltreatment within the context of classical conditioning. Biol Psychiatry 57: 823-831.

Rubino T, Parolaro D. 2016. The impact of exposure to cannabinoids in adolescence: insights from animal models. Biol Psychiatry 79: 578-585.

Rubino T, Realini N, Guidali C, Braida D, Capurro V, Castiglioni C, Cherubino F, Romualdi P, Candeletti S, Sala M. 2008. Chronic $\Delta$-tetrahydrocannabinol during adolescence provokes sex-dependent changes in the emotional profile in adult rats: behavioral and biochemical correlates. Neuropsychopharmacology 33: 2760-2771.

Rubino T, Realini N, Braida D, Guidi S, Capurro V, Vigano D, Guidali C, PinterM, Sala M, Bartesaghi R. 2009. Changes in hippocampalmorphology and neuroplasticity induced by adolescent THC treatment are associated with cognitive impairment in adulthood. Hippocampus 19: 763-772.

Rubino T, Prini P, Piscitelli F, Zamberletti E, Trusel M, Melis M, Sagheddu C, Ligresti A, Tonini R, Di Marzo V, Parolaro D. 2015. Adolescent exposure to THC in female rats disrupts developmental changes in the prefrontal cortex. Neurobiol Dis 73: 60-9.

Schneider M. 2013. Adolescence as a vulnerable period to alter rodent behavior. Cell Tissue Res 354: 99-106.

Schneider M, Koch M. 2003. Chronic pubertal, but not adult chronic cannabinoid treatment impairs sensorimotor gating, recognition memory, and the performance in a progressive ratio task in adult rats. Neuropsychopharmacology 28: 1760-1769.

Schneider M, Koch M. 2005. Deficient social and play behavior in juvenile and adult rats after neonatal cortical lesion: effects of chronic pubertal cannabinoid treatment. Neuropsychopharmacology 30: 944-957.

Schneider M, Koch M. 2007. The effect of chronic peripubertal cannabinoid treatment on deficient object recognition memory in rats after neonatal mPFC lesion. Eur Neuropsychopharmacol 17: 180-186.

Segev A, Akirav I. 2011. Differential effects of cannabinoid receptor agonist on social discrimination and contextual fear in amygdala and hippocampus. Learn Mem 18: 254-259.

Segev A, Rubin AS, Abush H, Richter-Levin G, Akirav I. 2013. Cannabinoid receptor activation prevents the effects of chronic mild stress on emotional learning and LTP in a rat model of depression. Neuropsychopharmacology 39: 919-933.

Shanmugan S, Epperson CN. 2014. Estrogen and the prefrontal cortex: towards a new understanding of estrogen's effects on executive functions in the menopause transition. Hum Brain Mapp 35: 847-865.

Sivukhina E, Schäfer HH, Jirikowski GF. 2013. Differences in colocalization of corticosteroid-binding globulin and glucocorticoid receptor immunoreactivity in the rat brain. Ann Anat 195: 219-224.

Spear LP. 2000. The adolescent brain and age-related behavioral manifestations. Neurosci Biobehav Rev 24: 417-63.

Steiner MA, Wotjak CT. 2008. Role of the endocannabinoid system in regulation of the hypothalamic-pituitary-adrenocortical axis. Prog Brain Res 170: $397-432$.

Tarullo AR, Gunnar MR. 2006. Child maltreatment and the developing HPA axis. Horm Behav 50: 632-639.

Trujillo V, Durando PE, Suárez MM. 2016. Maternal separation in early life modifies anxious behavior and Fos and glucocorticoid receptor expression in limbic neurons after chronic stress in rats: effects of tianeptine. Stress 19: 91-103.

Viveros MP, Marco EM, File SE. 2005. Endocannabinoid system and stress and anxiety responses. Pharmacol Biochem Behav 81: 331-342.

Viveros M-P, Llorente R, Suarez J, Llorente-Berzal A, Lopez-Gallardo M, de Fonseca FR. 2012. The endocannabinoid system in critical neurodevelopmental periods: sex differences and neuropsychiatric implications. J Psychopharmacol 26: 164-176.

Zamberletti E, Prini P, Speziali S, Gabaglio M, Solinas M, Parolaro D, Rubino T. 2012. Gender-dependent behavioral and biochemical effects of adolescent delta-9-tetrahydrocannabinol in adult maternally deprived rats. Neuroscience 204: 245-257.

Received January 6, 2016; accepted in revised form April 22, 2016. 


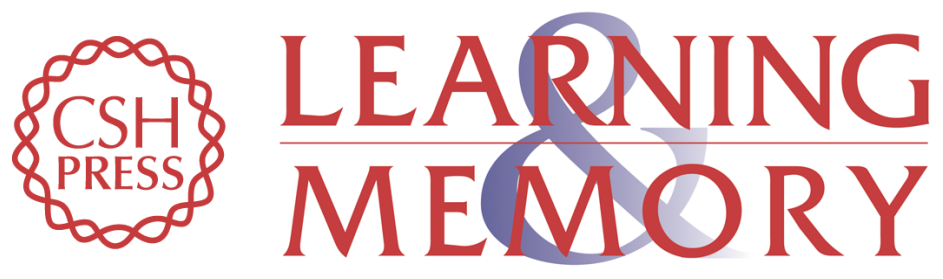

\section{Cannabinoids reverse the effects of early stress on neurocognitive performance in adulthood}

Shirley Alteba, Nachshon Korem and Irit Akirav

Learn. Mem. 2016, 23:

Access the most recent version at doi:10.1101/Im.041608.116

References This article cites 71 articles, 8 of which can be accessed free at:

http://learnmem.cshlp.org/content/23/7/349.full.html\#ref-list-1

Creative This article is distributed exclusively by Cold Spring Harbor Laboratory Press for the

Commons first 12 months after the full-issue publication date (see

License

http://learnmem.cshlp.org/site/misc/terms.xhtml). After 12 months, it is available under a Creative Commons License (Attribution-NonCommercial 4.0 International), as described at http://creativecommons.org/licenses/by-nc/4.0/.

Email Alerting Receive free email alerts when new articles cite this article - sign up in the box at the Service top right corner of the article or click here. 